\title{
Investigating the effect of in-service training on advisors' effectiveness through psychological empowerment
}

\author{
Farideh Dokaneheeifard $^{\mathrm{a}^{*}}$ and Mahnaz Jafari ${ }^{\mathrm{b}}$
}

${ }^{a}$ Assist. Prof. \& Faculty Member, Roudehen Branch, Islamic Azad University (RIAU), Roudehen, Iran ${ }^{b}$ M.Sc. Student, Roudehen Branch, Islamic Azad University (RIAU), Roudehen, Iran

\begin{tabular}{|c|c|}
\hline CHRON I C LE & A B S TRACT \\
\hline $\begin{array}{l}\text { Article history: } \\
\text { Received January 2, } 2015 \\
\text { Received in revised format } 6 \\
\text { February } 2015 \\
\text { Accepted } 24 \text { February } 2015 \\
\text { Available online } \\
\text { February } 262015 \\
\text { Keywords: } \\
\text { Psychological empowerment } \\
\text { Self- efficacy } \\
\text { Self-determination } \\
\text { Impact } \\
\text { Meaningfulness } \\
\text { Trust }\end{array}$ & $\begin{array}{l}\text { Efficiency is one of the fundamental concepts in any organization including ministry of } \\
\text { education of Iran. Teachers and counselors are the main assets of this organization and } \\
\text { education plays a key role in achieving the organization's goals. In-service training is a } \\
\text { technique for improving the quality and effectiveness of the advisors. This paper presents a } \\
\text { study on the effect of in-service training on advisors' effectiveness through psychological } \\
\text { empowerment. The study uses a questionnaire developed by Spreitzer (1995) [Spreitzer, G. M. } \\
\text { (1995). Psychological empowerment in the workplace: Dimensions, measurement, and } \\
\text { validation. Academy of management Journal, 38(5), 1442-1465.] to examine the effects of five } \\
\text { variables; namely self- efficacy, self-determination, impact, meaningfulness and trust. Using } \\
\text { structural equation modeling, the study has determined that all five psychological } \\
\text { empowerment components had positive and meaningful effects on in-service training. In } \\
\text { addition, in-service training maintained positive and meaningful impacts on all components on } \\
\text { psychological empowerment. Moreover, in-service training positively influenced on } \\
\text { psychological empowerment. }\end{array}$ \\
\hline
\end{tabular}

\section{Introduction}

Efficiency is one of the fundamental concepts in any organization including ministry of education. Teachers and counselors are the main assets of this organization and education plays a key role in achieving the organization's goals. In-service training is a technique for improving the quality and effectiveness of the advisors. There are several studies on measuring the effects psychological empowerment on different factors such as organizational commitment. Bani et al. (2014) presented a study on relationship between employees' psychological empowerment and organizational commitment in revenue agency of city of Semnan, Iran. The study applied two questionnaires, one for measuring the effects of psychological empowerment developed by Mishra and Spreitzer (1998) and the other for measuring organizational commitment developed by Meyer and Allen (1991). The results

*Corresponding author. Tel: +98-912-2995919

E-mail addresses ali55free@yahoo.com (M. Jafari) 
of the study indicated that there had been some positive and meaningful relationships between psychological empowerment and organizational commitment components including Sense of efficacy, meaningful, having a choice and trust. However, the survey did not support any relationship between Competency and organizational commitment.

Kheirkhah et al. (2014) determined critical factors affecting on organizational commitment. They chose the most important factors grouped in four categories and using factor analysis reported that Affective commitment, Continuous commitment, Moral commitment and Enduring commitment were the most important factors affecting organizational commitment. Miarkolaei and Miarkolaei (2014) investigated the relationship between employees' job satisfaction and organizational commitment of Red Crescent Society's Textile Industries of Islamic Republic of Iran by using Minnesota Satisfaction Questionnaire (MSQ) and Allen and Meyer's Organizational Commitment Questionnaires for collecting data (Allen \& Meyer, 1990). They stated significant relationships between employees' job satisfaction, organizational commitment, and their dimensions. Mirzaiefar (2014) studied Huber model on the effect of psychological empowerment of employees on organizational learning. They reported that psychological empowerment of employees could influence on organizational learning characteristics in organization, significantly. Alikhani et al. (2014) studied the relationship between social capital and organizational commitment by considering the relationship between social capital with three components of organizational commitment; namely, affective commitment, continuous and normative commitment. They stated that there were positive and meaningful relationships between social capital and affective commitment, continuous and normative commitment.

\section{The proposed study}

This paper presents a study on the effect of in-service training (IST) on advisors' effectiveness through psychological empowerment. The study uses a questionnaire developed by Spreitzer (1995) to examine the effects of five variables; namely self- efficacy (SEF), self-determination (SDE), impact (IMP), meaningfulness (MEA) and trust (TRU). The proposed study uses a sample of 92 teachers who accepted to participate in this survey. In terms of personal characteristics, 73 of them were female and 19 of them were male. In addition, 72 people hold bachelor degree of sciences and 20 of them hold master's degree. Fig. 1 demonstrates other personal characteristics of the participants.

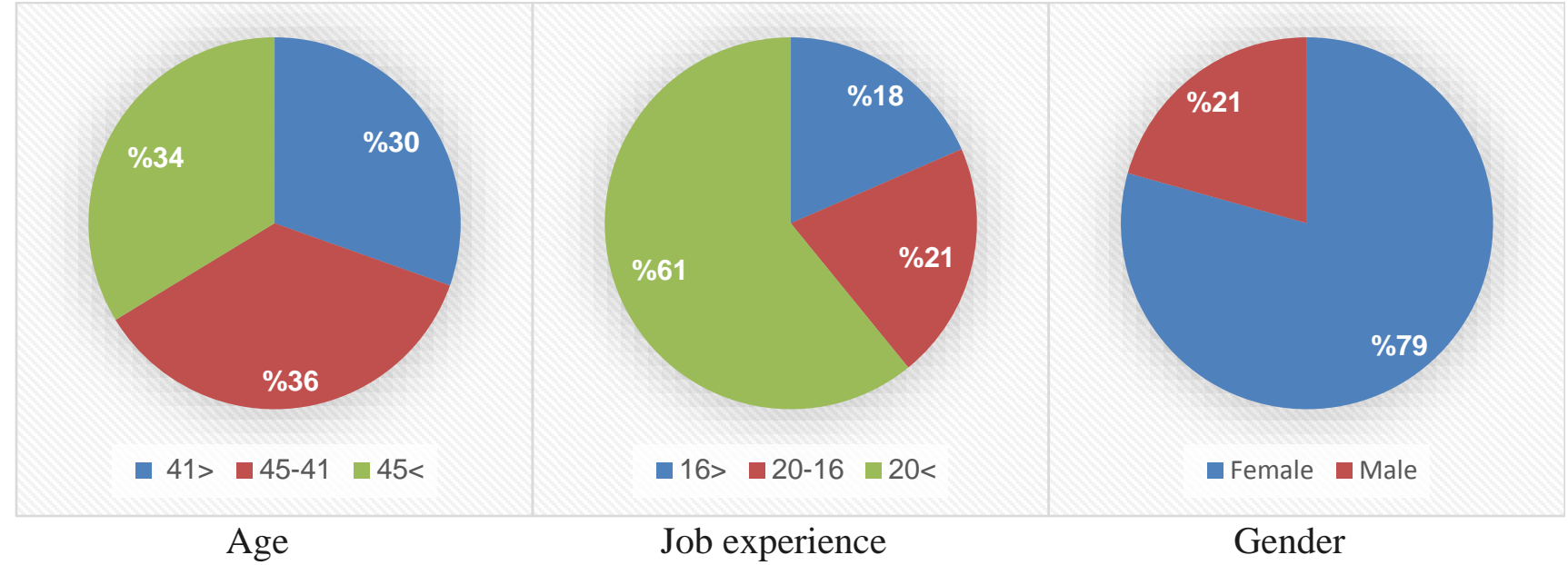

Fig. 1. Personal characteristics of the participants

As we can observe from the results of Fig. 1, most participants had, at least, 16 years of job experiences and they were mostly middle aged people. The study uses structural equation modeling to examine the effects of different factors on psychological empowerment on in-service training. Table 1 and Fig. 2 summarize the results of cross-loadings as well as loadings components. 
Table 1

The summary of Cross-loadings and loadings components

\begin{tabular}{|c|c|c|c|c|c|c|c|c|c|c|c|c|c|c|}
\hline \multicolumn{2}{|c|}{ Variable } & \multicolumn{7}{|c|}{ Cross-loadings } & \multicolumn{3}{|c|}{ loadings } & \multicolumn{3}{|c|}{ Composite } \\
\hline Latent & Manifest & IST & SEF & SDE & MEA & IMP & TRU & EEF & Factor & Error & Statistics & AVE & Alpha & (PCA) \\
\hline \multirow{9}{*}{ IST } & IST1 & 0.784 & 0.456 & 0.535 & 0.414 & 0.513 & 0.467 & 0.516 & 0.784 & 0.041 & 19. 123 & \multirow{9}{*}{0.680} & \multirow{9}{*}{0.941} & \multirow{9}{*}{0.951} \\
\hline & IST2 & 0.788 & 0.516 & 0.490 & 0.492 & 0.398 & 0.421 & 0.477 & 0.788 & 0.047 & 16. 816 & & & \\
\hline & IST3 & 0.850 & 0.479 & 0.602 & 0.480 & 0.476 & 0.441 & 0.441 & 0.850 & 0.027 & 31.966 & & & \\
\hline & IST4 & 0.840 & 0.320 & 0.413 & 0.412 & 0.418 & 0.388 & 0.363 & 0.840 & 0.039 & 21. 363 & & & \\
\hline & IST5 & 0.828 & 0.337 & 0.343 & 0.472 & 0.373 & 0.387 & 0.473 & 0.828 & 0.045 & 18. 593 & & & \\
\hline & IST6 & 0.841 & 0.406 & 0.412 & 0.376 & 0.528 & 0.452 & 0.378 & 0.841 & 0.030 & 27. 728 & & & \\
\hline & IST7 & 0.874 & 0.456 & 0.475 & 0.617 & 0.433 & 0.501 & 0.488 & 0.874 & 0.032 & 27. 260 & & & \\
\hline & IST8 & 0.816 & 0.469 & 0.454 & 0.436 & 0.393 & 0.375 & 0.469 & 0.816 & 0.063 & 12. 957 & & & \\
\hline & IST9 & 0.797 & 0.407 & 0.502 & 0.375 & 0.418 & 0.384 & 0.490 & 0.797 & 0.056 & 14. 341 & & & \\
\hline \multirow{3}{*}{ SEF } & SEF1 & 0.490 & 0.898 & 0.521 & 0.493 & 0.404 & 0.302 & 0.545 & 0.898 & 0.027 & 32.735 & \multirow{3}{*}{0.739} & \multirow{3}{*}{0.824} & \multirow{3}{*}{0.896} \\
\hline & SEF2 & 0.471 & 0.907 & 0.497 & 0.510 & 0.487 & 0.366 & 0.415 & 0.907 & 0.035 & 26. 138 & & & \\
\hline & SEF3 & 0.356 & 0.768 & 0.352 & 0.398 & 0.325 & 0.393 & 0.401 & 0.768 & 0.103 & 7. 482 & & & \\
\hline \multirow{3}{*}{ SDE } & SDE1 & 0.534 & 0.518 & 0.887 & 0.395 & 0.650 & 0.474 & 0.552 & 0.887 & 0.030 & 29. 967 & \multirow{3}{*}{0.729} & \multirow{3}{*}{0.814} & \multirow{3}{*}{0.893} \\
\hline & SDE2 & 0.438 & 0.359 & 0.881 & 0.234 & 0.571 & 0.356 & 0.514 & 0.881 & 0.027 & 32. 226 & & & \\
\hline & SDE3 & 0.490 & 0.522 & 0.790 & 0.408 & 0.568 & 0.413 & 0.576 & 0.790 & 0.061 & 13. 006 & & & \\
\hline \multirow{3}{*}{ MEA } & MEA1 & 0.478 & 0.514 & 0.288 & 0.887 & 0.241 & 0.455 & 0.539 & 0.887 & 0.039 & 22. 852 & \multirow{3}{*}{0.766} & \multirow{3}{*}{0.848} & \multirow{3}{*}{0.911} \\
\hline & MEA2 & 0.409 & 0.362 & 0.388 & 0.805 & 0.271 & 0.345 & 0.473 & 0.805 & 0.057 & 14. 242 & & & \\
\hline & MEA3 & 0.549 & 0.528 & 0.388 & 0.929 & 0.324 & 0.425 & 0.477 & 0.929 & 0.019 & 49. 403 & & & \\
\hline \multirow{3}{*}{ IMP } & IMP1 & 0.456 & 0.306 & 0.668 & 0.274 & 0.864 & 0.457 & 0.455 & 0.864 & 0.048 & 18. 048 & \multirow{3}{*}{0.696} & \multirow{3}{*}{0.780} & \multirow{3}{*}{0.874} \\
\hline & IMP2 & 0.461 & 0.476 & 0.521 & 0.203 & 0.863 & 0.460 & 0.447 & 0.863 & 0.046 & 18. 781 & & & \\
\hline & IMP3 & 0.418 & 0.445 & 0.530 & 0.323 & 0.773 & 0.471 & 0.427 & 0.773 & 0.063 & 12. 330 & & & \\
\hline \multirow{3}{*}{ TRU } & TRU1 & 0.488 & 0.483 & 0.432 & 0.552 & 0.459 & 0.909 & 0.523 & 0.909 & 0.020 & 45.645 & \multirow{3}{*}{0.762} & & \\
\hline & TRU2 & 0.440 & 0.235 & 0.257 & 0.317 & 0.383 & 0.844 & 0.355 & 0.844 & 0.063 & 13. 365 & & 0.843 & 0.908 \\
\hline & TRU3 & 0.423 & 0.274 & 0.522 & 0.313 & 0.576 & 0.865 & 0.446 & 0.865 & 0.038 & 22. 483 & & & \\
\hline & EEF1 & 0.410 & 0.355 & 0.423 & 0.499 & 0.364 & 0.527 & 0.760 & 0.760 & 0.081 & 9. 355 & & & \\
\hline & EEF2 & 0.425 & 0.450 & 0.503 & 0.484 & 0.318 & 0.429 & 0.804 & 0.804 & 0.049 & 16. 463 & & & \\
\hline FFF & EEF3 & 0.445 & 0.524 & 0.638 & 0.489 & 0.526 & 0.319 & 0.844 & 0.844 & 0.031 & 26. 980 & 582 & 858 & 0897 \\
\hline EEF & EEF4 & 0.462 & 0.430 & 0.496 & 0.352 & 0.546 & 0.534 & 0. 756 & 0.756 & 0.053 & 14. 392 & 0.582 & 0.858 & 0.897 \\
\hline & EEF5 & 0.436 & 0.266 & 0.384 & 0.423 & 0.208 & 0.295 & 0.717 & 0.717 & 0.075 & 9. 517 & & & \\
\hline & EEF6 & 0.298 & 0.311 & 0.283 & 0.356 & 0.238 & 0.303 & 0.687 & 0.687 & 0.071 & 9. 648 & & & \\
\hline
\end{tabular}

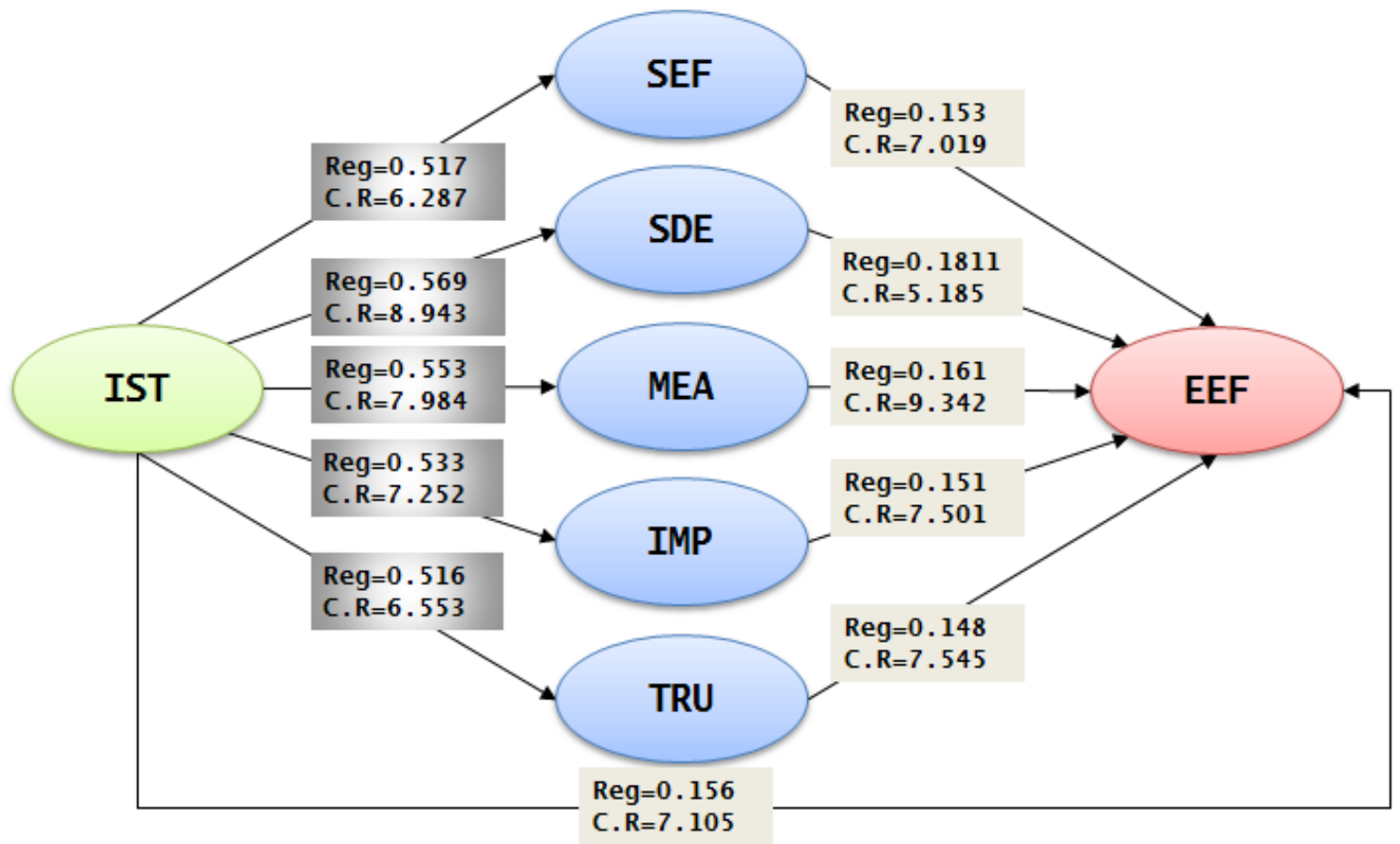

Fig. 2. The summary of structural equation modeling 


\section{Discussion and conclusion}

According to the results of Table 1 and Fig. 2, we can observe that all five psychological empowerment components had positive and meaningful effects on in-service training. In addition, in-service training maintained positive and meaningful impacts on all components on psychological empowerment. Moreover, in-service training positively influence on psychological empowerment. The results of this study are consistent with other studies (Bani et al., 2014; Alikhani et al., 2014).

\section{Acknowledgement}

The authors would like to thank the anonymous referees for constructive comments on earlier version of this paper.

\section{References}

Alikhani, A., Fadavi, A \& Mohseninia, S. (2014). An empirical investigation on relationship between social capital and organizational commitment. Management Science Letters, 4(2), 373-376.

Allen, N. J., \& Meyer, J. P. (1990). The measurement and antecedents of affective, continuance and normative commitment to the organization. Journal of Occupational Psychology, 63, 1-18.

Bani, M., Yasoureini, M \& Mesgarpour, A. (2014). A study on relationship between employees' psychological empowerment and organizational commitment. Management Science Letters, 4(6), 1197-1200.

Canipe, J. S. (2006). Relationships among trust, organizational commitment, perceived organizational support, and turnover intentions (Unpublished Doctoral Dissertation). San Deigo: Alliant International University.

Kheirkhah, H., SeyedAliAkbar, S \& Fathi, K. (2014). A survey on critical factors influencing organizational commitment. Management Science Letters, 4(4), 819-822.

Meyer, J. P., \& Allen, N. J. (1991). A three-component conceptualization of organizational commitment. Human resource management review, 1(1), 61-89.

Miarkolaei, H \& Miarkolaei, H. (2014). An investigation on relationship between employees' job satisfaction and organizational commitment. Management Science Letters, 4(4), 669-678.

Mirzaiefar, M. (2014). An application of Huber model on the effect of psychological empowerment of employees on organizational learning. Management Science Letters, 4(3), 479-484.

Mishra, A. K., \& Spreitzer, G. M. (1998). Explaining how survivors respond to downsizing: The roles of trust, empowerment, justice, and work redesign. Academy of management Review, 23(3), 567588.

Spreitzer, G. M. (1995). Psychological empowerment in the workplace: Dimensions, measurement, and validation. Academy of management Journal, 38(5), 1442-1465.

Turner, B. A., \& Chelladurai, P. (2005). Organizational and occupational commitment, intention to leave, and perceived performance of intercollegiate coaches. Journal of Sport Management, 19(2), 193-211. 